\title{
Effect of dyspnea on frailty stages and related factors in Taiwanese men with COPD
}

This article was published in the following Dove Press journal:

International Journal of COPD

\author{
Pei-Ju Chen' \\ Kuang-Yao Yang ${ }^{2,3}$ \\ Wann-Cherng Perng ${ }^{4}$ \\ Kuan-Chia Lin ${ }^{5,6}$ \\ Kwua-Yun Wang ${ }^{7}$ \\ 'School of Nursing, National Yang- \\ Ming University, Taipei, Taiwan, \\ Republic of China; ${ }^{2}$ Department \\ of Chest Medicine, Taipei Veterans \\ General Hospital, Taipei, Taiwan, \\ Republic of China; ${ }^{3}$ Institute of \\ Emergency and Critical Care \\ Medicine, School of Medicine, \\ National Yang-Ming University, \\ Taipei, Taiwan, Republic of China; \\ ${ }^{4}$ Department of Internal Medicine, \\ Tri-Service General Hospital, \\ National Defense Medical Center, \\ Taipei, Taiwan, Republic of China; \\ ${ }^{5}$ Institute of Hospital and Health Care \\ Administration, National Yang-Ming \\ University, Taipei, Taiwan, Republic \\ of China; ${ }^{6}$ Communty Medicine \\ Research Center, Preventive Medicine \\ Research Center, National Yang-Ming \\ University, Taipei, Taiwan, Republic of \\ China; ${ }^{7}$ Department of Nursing, Taipei \\ Veterans General Hospital, Taipei, \\ Taiwan, Republic of China
}

Correspondence: Kwua-Yun Wang Department of Nursing, Taipei Veterans General Hospital, No. 20I, Sec. 2, Shipai Rd., Beitou District, Taipei City II 17 , Taiwan, Republic of China

Tel +88 6255702245

$\mathrm{Fax}+886228752932$

Email kywang7@vghtpe.gov.tw
Purpose: Chronic obstructive pulmonary disease (COPD) impacts health-related quality of life in men more than in women. In patients with dyspnea, frailty is more likely to develop and aggravate disability. Despite this, few studies have addressed frailty in men with COPD. The present study investigated the effects of dyspnea and its related factors on frailty in men with COPD.

Patients and methods: This cross-sectional observational study selected 125 participants by voluntary sampling at the thoracic outpatient clinics of two medical centers in Taiwan. The modified Medical Research Council questionnaire was used as the basis to classify dyspnea. Data were collected using questionnaires and analyzed using IBM SPSS Statistics for Windows, version 24.0 (IBM Corporation., Armonk, NY, USA).

Results: There were $85.90 \%$ and $26.70 \%$ patients with COPD assessed in the unfit stage among the dyspnea and non-dyspnea groups, respectively. Additionally, the number of medication use and the COPD Assessment Test (CAT) scores were correlated with the period from fitness to unfitness among the dyspnea group and non-dyspnea group.

Conclusion: COPD with dyspnea was more common in the unfit stages. The total number of medication use and CAT scores were significantly related to frailty.

Keywords: chronic obstructive, dyspnea, frail elderly, men, pulmonary disease

\section{Introduction}

Chronic obstructive pulmonary disease (COPD) is a progressive and irreversible respiratory disease, and is more common in those who are middle-aged, male, smokers, and former smokers. The burden of COPD is going to increase in recent years due to exposure to more severe air pollution and a faster aging population. ${ }^{1}$ Studies have revealed that COPD patients with frailty face more risks to exposure than those without COPD, and it not only increases the negative health-related outcomes (eg, disability and mortality), but also places significant expenditure on health care resources. ${ }^{2-4}$ Among COPD patients, studies have also revealed that males have higher frailty prevalence than females due to higher smoking exposure and disease burden. ${ }^{5}$ Also, COPD patients undergoing dyspnea have an increased risk of frailty. ${ }^{6}$ If clinicians better understand the effects of dyspnea and its related factors on frailty, they may help the COPD men to delay dependency and disability. However, a retrospective analysis of the literatures showed that most studies have not been categorized by sex or considered the related factors on COPD patients with dyspnea or not in terms of frailty. As a result, it would be difficult to realize and provide suitable care for them. Thus, this study aimed to determine the effects of dyspnea and its related factors on frailty in men with COPD, and to serve as a reference for the clinical care of these patients in the future. 


\section{Materials and methods}

\section{Study design and procedure}

This was a cross-sectional, observational study at the thoracic outpatient clinics of the Taipei Veterans General Hospital and the Tri-Service General Hospital. After the Human Research Institutional Review Boards of two medical centers in Taiwan approved the study (approval number: 2015-03-005A, 1-103-05-162), the researchers explained the purpose of the study to patients who met the inclusion criteria, and the subjects completed a consent form. Next, patient demographic and disease characteristic data were collected using self-administered questionnaires. The modified Medical Research Council (mMRC) questionnaire was used to classify dyspnea. The COPD Assessment Test (CAT) questionnaire was used to classify and group the patients. The Center for Epidemiological Studies Depression Scale (CES-D) was used to identify patients with depression. Finally, the Chinese-Canadian Study of Health and Aging Clinical Frailty Scale (CSHA-CFS) was used to evaluate frailty. All patients who participated in this study signed an informed consent form.

\section{Samples}

GPOWER, ${ }^{7}$ a menu-driven program for IBM-compatible and Apple Macintosh personal computers, was used to estimate the required sample size, based on an effect size of 0.3 , a significance level of 0.05 , and a power of 0.95 . The required sample size was 111 subjects. With an estimated attrition rate of $20 \%$, the required sample size was 131 subjects. The inclusion criteria were International Classification of Disease (ICD) diagnostic codes 10.44-9, a history of smoking, and gender of male. Patients were excluded if they had a diagnosed cognitive mental disorder (ICD-10-CM: F00-99).

\section{Research tools}

\section{General characteristics}

The patients' general characteristics comprised demographic variables and disease characteristics. The demographic variables were age, educational attainment, income, smoking status, and body mass index (BMI), whereas the disease characteristics were the history of acute exacerbation of the last years, the Charlson Comorbidity Index, number of medication use, and pulmonary function. The content validity of the questionnaire results was 0.94 .

\section{Modified Medical Research Council questionnaire}

The mMRC questionnaire is used to evaluate dyspnea-related disability on a scale of $0-4$ based on the degree of dyspnea and restriction of activities. ${ }^{8}$ To achieve concurrent validation in this study, we calculated the Spearman rank correlation between the mMRC scores and CAT scores, which are commonly used to evaluate COPD. The result indicated that the mMRC and CAT scores were highly correlated and thus that they had good validity $(0.757, P<0.001)$. Additionally, re-testing for reliability yielded an interclass correlation coefficient (ICC) of 0.574. In data analysis, the mMRC score can be treated as a binary variable: $\mathrm{mMRC}$ scores of 0 or 1 represent no dyspnea, whereas those $\geq 2$ show dyspnea according to ABCD assessment tool of the 2018 Global Initiative for Chronic Obstructive Lung Disease (GOLD) update.

\section{COPD Assessment Test (CAT)}

The CAT questionnaire is used to evaluate and define the health status of patients with COPD. ${ }^{9}$ The test evaluates dyspnea, coughing, sputum production, wheezing, fatigue, sleep disturbance, daily activity status, feeling of control, and other items. Each item is scored from 0 (complete absence of the symptom or complication) to 5 (constant or frequent suffering from the symptom or complication), for a total score of 0-40. Because of copyright limitations, the scale could not be modified, so content validation was not performed in the present study. To ensure reliability, the coefficient of internal consistency was used, which yielded a Cronbach's $\alpha$ of 0.997 .

\section{Center for Epidemiological Studies Depression Scale}

This scale, developed by Radloff, ${ }^{10}$ evaluates depressed mood, feelings of guilt and worthlessness, psychomotor retardation, loss of appetite, and sleep disturbance. Subjects were interviewed about the frequency of the above symptoms in the past week. Each question was scored from 0 to 3, with a total score of $0-60$ for the 20 questions. Higher scores represented more severe depressive symptoms. Because of copyright limitations, the scale could not be modified, so content validation was not performed in this study. For reliability, the coefficient of internal consistency was used, which yielded a Cronbach's $\alpha>0.9$.

\section{Chinese-Canadian Study of Health and Aging Clinical Frailty Scale}

This scale was developed in Canada in 2010 to study health and aging through rapid screening for potentially frail older adults in communities. ${ }^{11}$ The scale scores frailty from 1 (very fit) to 7 (severely frail). Each level is defined as follows: Level 1 - very fit and robustly active, generally exercise regularly, and are the most fit for their age; Level 2 - well 
without significant disease complications, but less fit than individuals in Level 1; Level 3 - well with controlled disease, and symptoms are better controlled than in Level 4; Level 4 - no obvious dependency, but vulnerable, with the appearance of low-level symptoms and a greater likelihood that the patient will complain of symptoms; Level 5 - mildly frail, with evaluation results showing limitations in instrumental activities of daily living (IADLs), leading to dependence on others; Level 6 - moderately frail and requiring assistance for ADLs and IADLs; Level 7 - severely frail and completely dependent on others for ADLs, or terminally ill. Due to copyright limitations, the scale could not be modified, so content validation was not performed in this study. For reliability, the coefficient of internal consistency was used, which yielded a Cronbach's $\alpha>0.9$. For data analysis, the evaluation results were treated as a binominal variable as follows: fit and unfit. Fit was defined as Level 3 or below; unfit as Level 4 and above.

\section{Statistical analysis}

IBM SPSS Statistics for Windows, version 24.0 (IBM Corporation., Armonk, NY, USA) was used to analyze the experimental results. Descriptive statistics (mean, SD, and percentage) were used to report the subject characteristics in accordance with the purpose of the study. Inferential statistics (Student's $t$-test or Mann-Whitney U test, and chi-squared test) were used to compare independent variables between groups. Logistic regression analysis was used to determine frailty factors in patients with COPD. The level of significance was set at $P<0.05$.

\section{Results}

A total of 125 subjects were included in this study: 64 $(51.2 \%)$ with dyspnea and $61(48.8 \%)$ without.

\section{Demographic and disease characteristics}

Among the demographic characteristics, age and the proportion of patients who had only middle school education and below were significantly higher in the dyspnea group than in the non-dyspnea group. There were no significant differences between the groups in the other demographic characteristics (BMI, monthly income, and smoking status). In terms of the disease characteristics, more patients in the dyspnea group than in the non-dyspnea group had higher CAT scores, frequent exacerbation, and severe or worse respiratory tract obstruction. However, there were no significant differences between the groups in terms of Charlson Comorbidity Index score, number of medication use, and other variables (Table 1).

\section{Frailty status of patients with COPD and predictors for frailty stage}

The non-dyspnea group included 44 (73.3\%) fit individuals and $16(26.70 \%)$ unfit individuals. The dyspnea group included 9 (14.1\%) fit individuals and 55 (85.9\%) unfit individuals. The difference in this distribution was statistically significant ( $P=0.001$; Table 2 ). In terms of overall groups, using the fit group as a reference, analysis showed that the predictors for unfit were: age (odds ratio [OR] $=1.07$ ); high school or above $(\mathrm{OR}=0.45)$; number of medication use $(\mathrm{OR}=1.60)$; $\mathrm{CAT}$ scores $(\mathrm{OR}=1.21)$; and acute exacerbation (OR =1.89; Table 3).

The variables that had statistical significance in the overall analysis were used as a basis for the subgroup. After adjusting for age and education, the only predictor of unfit was CAT scores $(\mathrm{OR}=1.28)$ among non-dyspnea group using the fit group as a reference group.

It meant that an increased score of one in CAT scores corresponded to a 1.28 -fold increase in the risk of unfit among male COPD patients without dyspnea (Table 4). In the dyspnea group, the predictors for frailty was the number of medication use $(\mathrm{OR}=2.35)$ using the fit group as a reference group. It meant that every increase of one of medication use corresponded to a 2.35 -fold increase in unfit risk in male COPD patients with dyspnea (Table 5).

\section{Discussion}

This study showed that male COPD patients with dyspnea more often display unfit than those without dyspnea. It was difficult to compare with other studies because of their different populations, definition and measurement of frailty. However, COPD patients with dyspnea tended to have higher prevalence in frailty, which was consistent with previous studies. ${ }^{4,12}$ A possible reason for these findings is that individuals with dyspnea are more predisposed to a sedentary lifestyle and are more likely to have increased rates of low muscle strength and low muscle mass or strength is a symbol of frailty. ${ }^{13,14}$ Therefore, it could be understood why COPD patients with dyspnea are shown to be more unfit.

In addition, nearly $30 \%$ of patients had an unfit stage among COPD patients without dyspnea in this study. The percentage of unfit stage was in accordance within Dent's study regarding Asia-Pacific community-living older adults $(3.5 \%-27 \%) .{ }^{15}$ It has been reported that there was a positive correlation between frailty risk and COPD despite different instruments in the assessment of frailty. A prior study found that there were common risk factors (eg, aging and cigarette use $)^{16,17}$ and pathophysiology (systematic inflammation) among patients with frailty and COPD. In this study, the mean 
Table I Demographic variables and disease characteristics of COPD patients $(n=125)$

\begin{tabular}{|c|c|c|c|c|c|c|c|}
\hline \multirow[t]{2}{*}{ Variable } & \multicolumn{2}{|c|}{$\begin{array}{l}\text { Total } \\
(n=125,100 \%)\end{array}$} & \multicolumn{2}{|c|}{$\begin{array}{l}\text { Non-dyspnea group } \\
(n=6 I, 48.8 \%)\end{array}$} & \multicolumn{2}{|c|}{$\begin{array}{l}\text { Dyspnea group } \\
(\mathrm{n}=64,51.2 \%)\end{array}$} & \multirow[t]{2}{*}{$P$-value } \\
\hline & Mean & SD & Mean & SD & Mean & SD & \\
\hline Age (years) ${ }^{\mathrm{a}}$ & 77.36 & 10.26 & 72.15 & 10.84 & 78.42 & 8.70 & $<0.00 I^{\mathrm{d}}$ \\
\hline Body mass index & 23.07 & 3.63 & 23.24 & 3.25 & 22.91 & 3.97 & 0.62 \\
\hline $\mathrm{CAT}^{\mathrm{a}}$ & 13.97 & 9.83 & 8.18 & 6.45 & 19.48 & 9.35 & $<0.001^{d}$ \\
\hline Exacerbation (times/last year) ${ }^{\mathrm{a}}$ & 0.64 & 0.71 & 0.48 & 0.79 & 0.80 & 0.60 & $<0.00 I^{\mathrm{d}}$ \\
\hline Number of medications used & 2.39 & 1.16 & 2.21 & 1.08 & 2.56 & 1.22 & 0.093 \\
\hline \multirow[t]{2}{*}{ CES-D ${ }^{a}$} & 9.59 & 6.34 & 8.25 & 5.08 & 10.88 & 7.14 & 0.07 \\
\hline & $\begin{array}{l}\text { Number } \\
\text { of subjects }\end{array}$ & $\%$ & $\begin{array}{l}\text { Number } \\
\text { of subjects }\end{array}$ & $\%$ & $\begin{array}{l}\text { Number } \\
\text { of subjects }\end{array}$ & $\%$ & \\
\hline Educational attainment & & & & & & & $0.04^{c}$ \\
\hline Middle school or below & 71 & 56.80 & 29 & 47.50 & 42 & 65.60 & \\
\hline High school or above & 54 & 43.20 & 32 & 52.50 & 22 & 34.40 & \\
\hline Monthly income (NT\$) & & & & & & & 0.19 \\
\hline$\leq 16,304$ & 79 & 63.20 & 35 & 57.40 & 44 & 68.80 & \\
\hline$\geq 16,305$ & 46 & 36.80 & 26 & 42.60 & 20 & 31.30 & \\
\hline Smoking status & & & & & & & 0.48 \\
\hline Smoker & 28 & 22.40 & 12 & 19.70 & 16 & 25.00 & \\
\hline Non-smoker & 97 & 77.60 & 49 & 80.30 & 48 & 75.00 & \\
\hline Charlson Comorbidity Index & & & & & & & 0.98 \\
\hline I & 91 & 72.80 & 44 & 73.33 & 47 & 73.44 & \\
\hline 2 & 20 & 16.00 & 10 & 16.67 & 10 & 15.63 & \\
\hline$\geq 3$ & 13 & 10.40 & 6 & 10 & 7 & 10.94 & \\
\hline Lung function (FEV , pred\%) ${ }^{\mathrm{b}}$ & & & & & & & $0.01^{\mathrm{c}}$ \\
\hline Mild obstruction & 24 & 19.20 & 9 & 14.80 & 15 & 23.40 & \\
\hline Moderate obstruction & 67 & 53.60 & 41 & 67.20 & 26 & 40.60 & \\
\hline Severe or worse obstruction & 34 & 27.20 & 11 & 18.00 & 23 & 36.00 & \\
\hline
\end{tabular}

Notes: ${ }^{a}$ Mann-Whitney $U$ test; ${ }^{b}$ Lung function was used to stratify the severity of airway obstruction according to GOLD severity definition. ${ }^{c} P<0.05$; ${ }^{d} P<0.00$ I.

Abbreviations: CES-D, Center for Epidemiologic Studies Depression Scale; FEV, pred\%, predicted percentage for the forced expiratory volume during the first second; CAT, chronic obstructive pulmonary disease assessment test.

CAT score was $6.43 \pm 5.09$ in non-dyspnea patients under fit stage and $13.50 \pm 6.95$ in non-dyspnea patients under the unfit stage, respectively $(P<0.001)$. This study revealed that the disease burden of the unfit group was significantly higher than the fit group in non-dyspnea patients. The logistic regression analysis also showed that higher CAT scores were associated with higher frailty risk in non-dyspnea patients. It might be the reason to explain why nearly $30 \%$ of patients had the unfit stage among COPD patients without dyspnea.

Because frailty is a dynamic change, the results of this study showed that frailty in patients with COPD without dyspnea is affected by CAT and in those with dyspnea is affected by number of medication use. CAT is a multidimensional instrument to evaluate the health status impairment among COPD, and it is not only an indicator associated with acute exacerbation, ${ }^{18,19}$ symptom burden, ${ }^{20} \mathrm{COPD}$ severity ${ }^{21}$ but also correlated with systemic inflammation mediators..$^{22}$ Inflammation is a core element of the cycle of frailty through interrupted muscle mass and the induction of age-related pathological processes, ${ }^{23-25}$ and an article by Hubbard et $\mathrm{a}^{26}$ evaluated significant associations between frailty and inflammations. The findings demonstrated that

Table 2 Frailty stage of COPD patients with different degrees of dyspnea $(n=124)$

\begin{tabular}{|c|c|c|c|c|c|}
\hline \multirow[t]{2}{*}{ Variable } & \multicolumn{2}{|l|}{$\begin{array}{l}\text { Non-dyspnea group } \\
(n=60,48.39 \%)\end{array}$} & \multicolumn{2}{|l|}{$\begin{array}{l}\text { Dyspnea group } \\
(\mathrm{n}=64,51.61 \%)\end{array}$} & \multirow[t]{2}{*}{$P$-value } \\
\hline & Number of subjects & $\%$ & Number of subjects & $\%$ & \\
\hline Frailty evaluation results & & & & & $<0.00 I^{\mathrm{a}}$ \\
\hline Fit & 44 & 73.30 & 9 & 14.10 & \\
\hline Unfit & 16 & 26.70 & 55 & 85.90 & \\
\hline
\end{tabular}

Note: ${ }^{a}<<0.001$. 
Table 3 Predictors of frailty in COPD patients: overall

\begin{tabular}{|c|c|c|c|}
\hline \multirow[t]{2}{*}{ Variable } & \multicolumn{3}{|c|}{ Unfit vs fit (ref) } \\
\hline & OR & $95 \% \mathrm{Cl}$ & $P$-value \\
\hline \multicolumn{4}{|l|}{ Demographic characteristic } \\
\hline Age & 1.07 & (I.034-I.II9) & $<0.00 I^{c}$ \\
\hline \multicolumn{4}{|l|}{ Educational attainment } \\
\hline High school or above & 0.45 & $(0.217-0.931)$ & $0.03 \mathrm{I}^{\mathrm{a}}$ \\
\hline \multicolumn{4}{|l|}{ Middle school or below (ref) } \\
\hline \multicolumn{4}{|l|}{ Monthly income } \\
\hline$\geq 16,305$ & 0.63 & $(0.299-1.305)$ & 0.211 \\
\hline \multicolumn{4}{|l|}{$\leq 16,304$ (ref) } \\
\hline \multicolumn{4}{|l|}{ Smoking status } \\
\hline Ex-smoker & 0.45 & $(0.182-1.129)$ & 0.089 \\
\hline \multicolumn{4}{|l|}{ Smoker (ref) } \\
\hline \multicolumn{4}{|l|}{ Disease characteristics } \\
\hline Number of medications used & 1.60 & $(I .14 I-2.250)$ & $0.007^{b}$ \\
\hline CAT & 1.21 & $(1.128-1.301)$ & $<0.001^{\mathrm{c}}$ \\
\hline Exacerbation & 1.89 & $(1.031-3.459)$ & $0.040^{\mathrm{a}}$ \\
\hline \multicolumn{4}{|l|}{ Charlson Comorbidity Index } \\
\hline$\geq 3$ & 1.37 & $(0.4|7-4.5| 2)$ & 0.603 \\
\hline 2 & 2.00 & $(0.706-5.5 \mid 2)$ & 0.192 \\
\hline \multicolumn{4}{|l|}{ I (ref) } \\
\hline \multicolumn{4}{|c|}{ Degree of respiratory tract obstruction } \\
\hline Severe or worse & 1.39 & $(0.444-4.345)$ & 0.572 \\
\hline Moderate & 0.42 & $(0.157-1.107)$ & 0.079 \\
\hline \multicolumn{4}{|l|}{ Mild (ref) } \\
\hline Depression & 1.05 & $(0.988-1.116)$ & 0.114 \\
\hline
\end{tabular}

Notes: Univariate logistic regression $(O R)$. ${ }^{a} P<0.05$. ${ }^{b} P<0.01 .{ }^{c} p<0.001$. Abbreviations: OR, odds ratio; ref, reference group; CAT, COPD Assessment Test.

CAT could be a useful indicator for predicting COPD patients from fit to unfit.

Although there was no significant difference in the number of medication use between patients with or without dyspnea, the patients with dyspnea group demonstrated that the older and the higher the CAT scores, the higher the incidence of acute exacerbation and worse pulmonary function than those without dyspnea. The possible reason might be that aging-related changes affected pharmacokinetics, such

Table 4 Predictors of frailty stage in men with COPD: nondyspnea group $(n=60)$

\begin{tabular}{llll}
\hline Variable & \multicolumn{4}{l}{ Unfit vs fit (ref) } \\
\cline { 2 - 4 } & $\begin{array}{l}\text { Adjusted } \\
\text { OR }\end{array}$ & 95\% Cl & P-value \\
\hline CAT & I.28 & $(1.093-1.486)$ & $0.002^{\mathrm{a}}$ \\
Number of medications used & I.62 & $(0.780-3.367)$ & 0.196 \\
Acute exacerbation & 0.49 & $(0.140-1.680)$ & 0.254 \\
\hline
\end{tabular}

Notes: Multivariate logistic regression - controlled for age, education attainment. ${ }^{a} \mathrm{P}<0.01$.

Abbreviations: OR, odds ratio; ref, reference group; CAT, COPD Assessment Test.
Table 5 Predictors of frailty stage in men with COPD: dyspnea group $(n=64)$

\begin{tabular}{llll}
\hline Variable & \multicolumn{3}{l}{ Unfit vs fit (ref) } \\
\cline { 2 - 4 } & $\begin{array}{l}\text { Adjusted } \\
\text { OR }\end{array}$ & 95\% Cl & P-value \\
\hline CAT & 1.08 & $(0.972-1.199)$ & 0.153 \\
Number of medications used & 2.35 & $(1.002-5.519)$ & $0.050^{\mathrm{a}}$ \\
Acute exacerbation & 2.55 & $(0.542-11.969)$ & 0.237 \\
\hline
\end{tabular}

Notes: Multivariate logistic regression - controlled for age, education attainment. ap $<0.05$.

Abbreviations: OR, odds ratio; ref, reference group; CAT, COPD Assessment Test.

as reduced drug clearance and increased drug accumulation, ${ }^{27}$ and disease-related distress increased the chances of taking multiple medications among COPD. ${ }^{28,29}$ This leads to an increase in the risk of medication side effects, for instance, impaired mobility, malnutrition, hospitalization, ${ }^{30}$ and also increased the risk of frailty. ${ }^{31,32}$ Besides, among older adults, multiple medication use not only represents multiple illnesses or the result of inappropriate medication, but also revealed knowledge of medication use becoming more inadequate, increasing the risk of exposure to medication-related adverse reactions. ${ }^{33,34}$ It might be the reason that the number of medication use is related to the progression from fit to unfit.

\section{Conclusion}

The present study showed that male COPD patients with dyspnea numbered more than half as unfit, and the number of medication use was independently associated with being unfit. Among non-dyspnea patients with COPD men, the CAT scores were associated with being assessed as unfit. Because frailty is common among patients with COPD with dyspnea, it not only affects the maintenance of health-related quality of life but also increases the frequency of medical resource utilization. Thus, the study results can provide important information on early and efficient detection of frailty-related factors. Using the frailty-related factors as the basis for intervention development can help patients to avoid exposure factors and negative health outcomes such as disability and death. In addition, this study incorporated consideration of gender difference, thus providing more specific results as a reference for the intervention development and individualized care. There were limited studies that discussed the associations between COPD males and frailty status. The present study excluded patients with cognitive mental disorder. Therefore, our findings could be affected by the exclusion of patients with cognitive mental disorder. This is a limitation in this study. However, the present study aimed to explore 
the factors associated with frailty in males with COPD but without cognitive mental disorder. This study still highlights the importance of frailty risk in COPD patients.

In the future, aside from frailty-related evaluation of patients with COPD using the demographic, disease characteristic, and psychiatric factors evaluated in this study, other tools including level inflammatory chemokines (eg, interleukins, tumor necrosis factors, and C-reactive protein), hormones, and muscle content can also be used to make objective evaluations in advance. Considering the acute attacks and dynamic change characteristics experienced by patients with COPD, subgroup classification based on the acute attack stage or degree of obstruction at different stages and the evaluation and comparison of the relationships and effects between these subgroups and frailty can assist in the clinical care and provide a reference for the customized care of these patient groups.

\section{Acknowledgments}

The present study was supported by the Department of Nursing and the Department of Chest Medicine of Taipei Veterans General Hospital, as well as by the Department of Pulmonary Medicine, Tri-Service General Hospital. The work was carried out in co-operation with the National Defense Medical Center.

\section{Author contributions}

All authors contributed toward data analysis, drafting and critically revising the paper and agree to be accountable for all aspects of the work.

\section{Disclosure}

The author reports no conflicts of interest in this work.

\section{References}

1. Global Initiative for Chronic Obstructive Lung Disease (GOLD). Global strategy for the diagnosis, management, and prevention of chronic obstructive pulmonary disease (2018 report); 2018. Available from: http://goldcopd.org. Accessed 13 March, 2018.

2. Bernabeu-Mora R, García-Guillamón G, Valera-Novella E, GiménezGiménez LM, Escolar-Reina P, Medina-Mirapeix F. Frailty is a predictive factor of readmission within 90 days of hospitalization for acute exacerbations of chronic obstructive pulmonary disease: a longitudinal study. Ther Adv Respir Dis. 2017;11(10):383-392.

3. Galizia G, Cacciatore F, Testa G, et al. Role of clinical frailty on longterm mortality of elderly subjects with and without chronic obstructive pulmonary disease. Aging Clin Exp Res. 2011;23(2):118-125.

4. Park SK, Richardson CR, Holleman RG, Larson JL. Frailty in people with COPD, using the National Health and Nutrition Evaluation Survey dataset (2003-2006). Heart Lung. 2013;42(3):163-170.

5. Aryal S, Diaz-Guzman E, Mannino DM. Influence of sex on chronic obstructive pulmonary disease risk and treatment outcomes. Int J Chron Obstruct Pulmon Dis. 2014;9:1145.
6. Lahousse L, Ziere G, Verlinden VJ, et al. Risk of frailty in elderly with COPD: a population-based study. J Gerontol A Biol Sci Med Sci. 2016;71(5):689-695.

7. Erdfelder E, Faul F, Buchner A. GPOWER: A general power analysis program. Behav Res Meth Instrum Computers. 1996;28(1):1-11.

8. Mahler DA, Wells CK. Evaluation of clinical methods for rating dyspnea. Chest. 1988;93(3):580-586.

9. Jones PW, Harding G, Berry P, et al. Development and first validation of the COPD Assessment Test. Eur Respir J. 2009;34(3):648-654.

10. Radloff LS. The CES-D scale: a self-report depression scale for research in the general population. Appl Psychol Meas. 1977;1(3):385-401.

11. Chan DC, Tsou HH, Chen CY, Chen CY. Validation of the ChineseCanadian study of health and aging clinical frailty scale (CSHA-CFS) telephone version. Arch Gerontol Geriatr. 2010;50(3):e74-e80.

12. Lahousse L, Verlinden VJ, van der Geest JN, et al. Gait patterns in COPD: the Rotterdam Study. Eur Respir J. 2015;46(1):88-95.

13. Barriga S, Rodrigues F, Bárbara C. Factors that influence physical activity in the daily life of male patients with chronic obstructive pulmonary disease. Rev Port Pneumol. 2014;20(3):131-137.

14. Landi F, Calvani R, Cesari M, et al. Sarcopenia as the biological substrate of physical frailty. Clin Geriatr Med. 2015;31(3):367-374.

15. Dent E, Lien C, Lim WS, et al. The Asia-Pacific Clinical Practice Guidelines for the Management of Frailty. J Am Med Dir Assoc. 2017; 18(7):564-575.

16. Dyer C. The interaction of ageing and lung disease. Chron Respir Dis. 2012;9(1):63-67.

17. Kojima G, Iliffe $S$, Walters K. Smoking as a predictor of frailty: a systematic review. BMC Geriatr. 2015;15(1):131.

18. Miravitlles M, García-Sidro P, Fernández-Nistal A, et al. The chronic obstructive pulmonary disease assessment test improves the predictive value of previous exacerbations for poor outcomes in COPD. Int JChron Obstruct Pulmon Dis. 2015;10:2571.

19. Han MK, Quibrera PM, Carretta EE, et al. Frequency of exacerbations in patients with chronic obstructive pulmonary disease: an analysis of the SPIROMICS cohort. Lancet Respir Med. 2017;5(8):619-626.

20. Kelly JL, Bamsey O, Smith C, et al. Health status assessment in routine clinical practice: the chronic obstructive pulmonary disease assessment test score in outpatients. Respiration. 2012;84(3):193-199.

21. Jones PW, Brusselle G, dal Negro RW, et al. Properties of the COPD assessment test in a cross-sectional European study. Eur Respir J. 2011;38(1):29-35.

22. Tu YH, Zhang Y, Fei GH. Utility of the CAT in the therapy assessment of COPD exacerbations in China. BMC Pulm Med. 2014;14(1):42.

23. Chung HY, Cesari M, Anton S, et al. Molecular inflammation: underpinnings of aging and age-related diseases. Ageing Res Rev. 2009;8(1): $18-30$.

24. Espinoza SE, Fried LP. Risk factors for frailty in the older adult. Clin Geriat. 2007;15(6):37.

25. Lang PO, Michel JP, Zekry D. Frailty syndrome: a transitional state in a dynamic process. Gerontology. 2009;55(5):539-549.

26. Hubbard RE, O'Mahony MS, Savva GM, Calver BL, Woodhouse KW. Inflammation and frailty measures in older people. J Cell Mol Med. 2009; 13(9B):3103-3109.

27. Mangoni AA, Jackson SH. Age-related changes in pharmacokinetics and pharmacodynamics: basic principles and practical applications. $\mathrm{Br}$ J Clin Pharmacol. 2004;57(1):6-14.

28. Franssen FM, Spruit MA, Wouters EF. Determinants of polypharmacy and compliance with GOLD guidelines in patients with chronic obstructive pulmonary disease. Int J Chron Obstruct Pulmon Dis. 2011;6:493.

29. Jyrkkä J, Enlund H, Korhonen MJ, Sulkava R, Hartikainen S. Patterns of drug use and factors associated with polypharmacy and excessive polypharmacy in elderly persons. Drugs Aging. 2009;26(6):493-503.

30. Frazier SC. Health outcomes and polypharmacy in elderly individuals. J Gerontol Nurs. 2005;31(9):4-9.

31. Gnjidic D, Hilmer SN, Blyth FM, et al. High-risk prescribing and incidence of frailty among older community-dwelling men. Clin Pharmacol Ther. 2012;91(3):521-528. 
32. Gnjidic D, Hilmer SN, Blyth FM, et al. Polypharmacy cutoff and outcomes: five or more medicines were used to identify community-dwelling older men at risk of different adverse outcomes. J Clin Epidemiol. 2012;65(9):989-995.

33. Fialová D, Topinková E, Gambassi G, et al. Potentially inappropriate medication use among elderly home care patients in Europe. JAMA. 2005;293(11):1348-1358.
34. Goulding MR. Inappropriate medication prescribing for elderly ambulatory care patients. Arch Intern Med. 2004;164(3):305-312.

International Journal of COPD

\section{Publish your work in this journal}

The International Journal of COPD is an international, peer-reviewed journal of therapeutics and pharmacology focusing on concise rapid reporting of clinical studies and reviews in COPD. Special focus is given to the pathophysiological processes underlying the disease, intervention programs, patient focused education, and self management protocols.
Dovepress

This journal is indexed on PubMed Central, MedLine and CAS. The manuscript management system is completely online and includes a very quick and fair peer-review system, which is all easy to use. Visit http://www.dovepress.com/testimonials.php to read real quotes from published authors.

Submit your manuscript here: http://www.dovepress.com/international-journal-of-chronic-obstructive-pulmonary-disease-journal 